\title{
对我国现代板内运动状况的初步探讨
}

\author{
丁 国 瑜 \\ （国家地屡局，北京） \\ 卢 演 俦 \\ （国家地震局地质研究所, 北京)
}

探讨亚洲东部这一新构造变形强烈区域,尤其是中国境内现代的应变和运动状况, 是一个 很有意义的课题.根据地震资料可获得对板内地壳瞬时的或短期的应变和运动状况的认识,但 是鉴于地震活动在时间上分布的不均匀性和地震记录的时间不够长, 探讨板内变形和运动的 基本状况还有赖于地质资料，特别是有关活动构造资料的应用.

在我国,晚第三纪以来的活动断裂十分发育,近年来对它们进行了大量的调查与研究, 积 累了丰富的资料，为探讨我国大陆内部各个块体的相对运动和总的变形情况提供了重要的基 础 ${ }^{[1]}$. 我国主要的活断层多数是继承性地分布于一些刚性或准刚性块体和巨型慴䏢带的边 缘. 是板内的主要活动边界. 活断层两盘的相对运动是在三维空间里进行的, 为了直观地反 映新构造期(尤其是近几万年来)块体水平相对运动状况，我们采用断裂两盘在水平面上相对 运动的平均速率矢量即两盘相对滑动的平均速率矢量的水平投影值 $(\boldsymbol{V})$ 来表示.

$$
V=V_{1}+V_{2},
$$

这里 $\boldsymbol{V}_{1}$ 和 $\boldsymbol{V}_{2}$ 分别为平行于和垂直于断层线的平均滑动速率矢量. 它们的量值关系为

$$
\left.\begin{array}{rl}
|V| & =\left|\sqrt{V_{1}^{2}+V_{2}^{2}}\right|, \\
V_{1} & =u_{1} / t, \\
V_{2} & =u_{2} / t=h \cdot \operatorname{ctg} \alpha / t, \\
\theta & =\operatorname{Arctg} V_{2} / V_{1},
\end{array}\right\}
$$

式中 $u_{1}$ 和 $u_{2}$ 分别为在 $t$ 时间里平行于和垂直于断㧁线的总错距, $h$ 为 $t$ 时间里两盘铅垂落差 (即两盘差异性升降幅度)， $\alpha$ 为断裂面倾角, $\theta$ 为水平面内断裂两盘错动方向与断层线的夹 角.

对中国各地主要活断层的错动资料按上述方法进行了整理和分析, 已获得百余个观察段 上断层滑动平均速率矢量的水平投影值的数据, 其中一部分表示在图 1 上.

这些资料表明,我国大陆内块体边界上活断层的滑动速率比板块边界上的小约 1-2 个数 量级, 但又明显地大于块体内部的运动速率. 以南北带 (约 $104^{\circ} \mathrm{E}$ ) 为界, 西部块体边界上的 平均水平滑动速率一般为 5-10 mm $\cdot \mathrm{y}^{-1}$, 块体内的通常为 $1-3 \mathrm{~mm} \cdot \mathrm{y}^{-1}$ 或更小些; 东部各块 体边界上的通常为 $1-4 \mathrm{~mm} \cdot \mathrm{y}^{-1}$, 块体内的往往小于 $0.5-1.0 \mathrm{~mm} \cdot \mathrm{y}^{-1}$. 活断层滑动速率的这 种大小分布格局与地震活动强弱的空间分布大体相吻合. 这反映出我国板内变形和运动具有

本文 1986 年 1 月 20 日收到. 


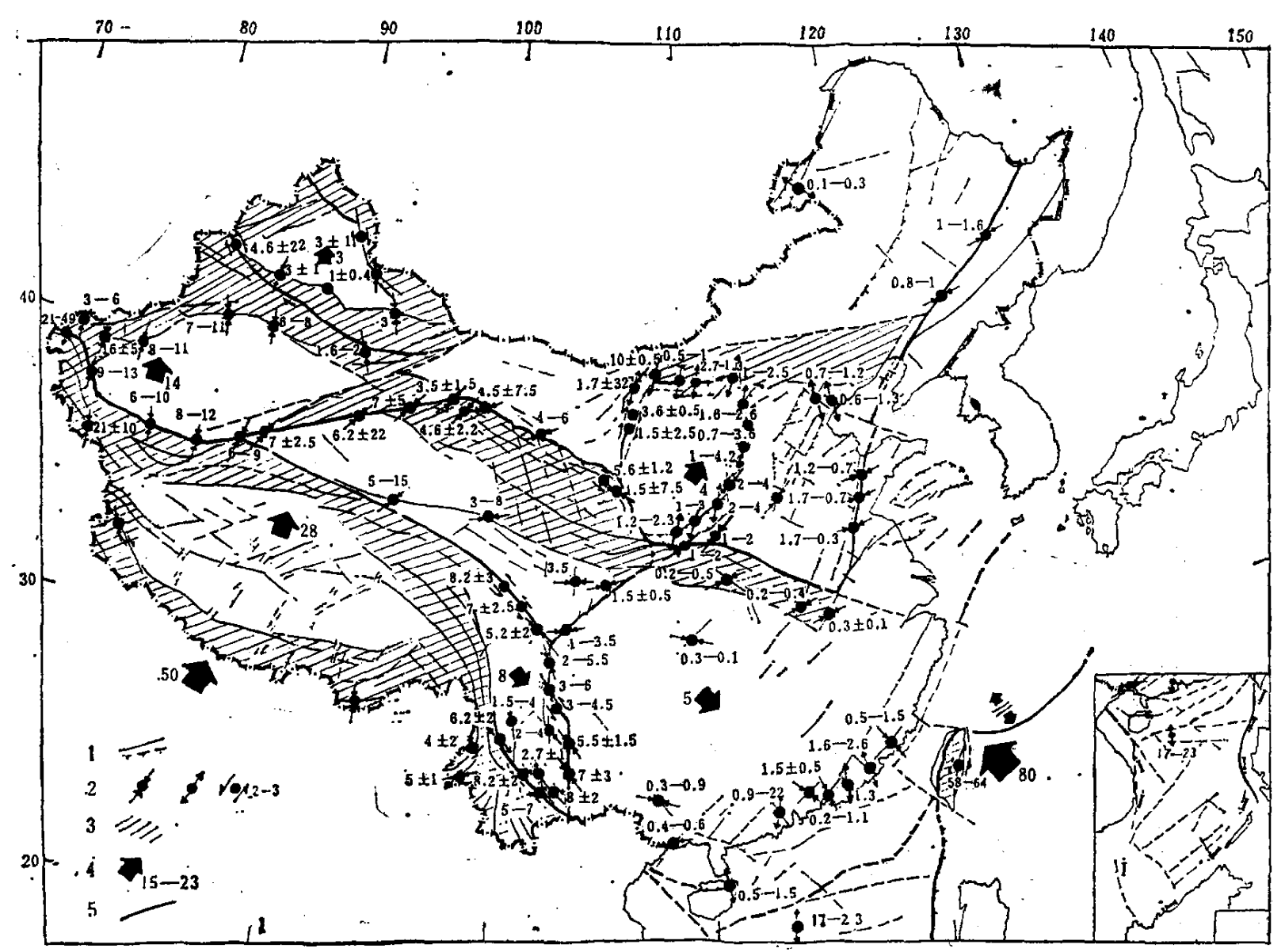

图 1 中国活断层平均水平滑动速率矢量及板内现代运动状况图

1. 活断层； 2 . 活断层水平滑动平均速率 (水平投影值, $\mathrm{mm} \cdot \mathrm{y}^{-1}$ ) 及方向 (挤压、拉张及走滑三类); 3. 袹级带 (新造山带)； 4 . 块体或禇皱带运动方向及速率 $\left(\mathrm{mm} \cdot \mathrm{y}^{-1}\right) ; 5$. 主要运动边界

以块体为单位的特征, 看来不尽符合均匀连续介质变形和位移的模式。

大陆板内地质历史和结构的复杂性导致其应变和相对运动状况比简单的刚性块体所表现 的要复杂的多 ${ }^{[2,3]}$. 从图 1 可看出, 相当多的块体边界具有压扭或张扭的复杂运动性质, 反映 边界两侧块体作斜冲或斜拉的相对运动。但从总体上看,在反映块体间相对运动上,块体边界 类型与板块边界相类似，基本上可分为聚敛(挤压逆冲)型，剪切（走滑）型和拉张 (裂陷) 型 三类. 由各类边界上活断层滑动的平均速率和方向 (图 1) 可以得到相邻两块体间相对运动速 率和方向的估计，但这只是反映了相邻两块体的相对运动状况。要确定各个块体的实际运动 或绝对运动速率和方向要涉及到板内块体运动的发动者和参考系 (不动点)，以及块体边界和 内部的物理力学性质. 大陆板内一般可划分为刚性或准刚性块体和塑性变形较显著的袹铍造 山带. 此外还有一些处于这二者性质之间的变形地带. 对于我国西部，块体间的相对运动以 及一些刚性块体及其相临的褔铍带的变形状况与印度板块相对于欧亚板块向北运动有密切关 系. 印度板块向北运动是我国西部各个块体和褶皱带运动和变形的根源. 内陆各地形变的情 况表明,许多地带都不是纯刚性体,而是具有不同塑性变形性质又具有传递力和速度的弹塑性 体. 这样,印度板块向北约 $50 \mathrm{~mm} \cdot \mathrm{y}^{-1}$ 的运动 ${ }^{[3]}$ 除了被各块体，尤其是块体间的褶皱带的变形 吸收一部分外,其余部分沿块体和褶皱带逐次向前传递.

为了得出各个块体向北相对运动速率的估计值，我们主要利用了西部各块体和袹皱带晚

第 18 期

科学 通报

1413 
第三纪夷平面变形抬升幅度及褶皱带两侧断裂逆冲速率的资料, 来大体估算了各个块体和裮 波带的缩短变形速率 (即印度板块向北运动速率因块体变形而被吸收的部分). 方法、步骤及 所得结果列于表 1 及图 1 上. 图 1 中各个块体的运动方向是根据新褶坡轴和活动逆冲断层走 向在水平面上垂直方向的展布状况而确定的. 它们与研究区域内震源主压应力轴方位的展布 基本一致 ${ }^{[4-6]}$.

表 1 中国西部块体和褶皱带形变和运动速率估计值

\begin{tabular}{|c|c|c|c|c|c|c|c|c|}
\hline \multirow{2}{*}{$\begin{array}{l}\text { 块体和 } \\
\text { 䙫练带 }\end{array}$} & \multirow{2}{*}{$\begin{array}{c}\text { 平面蒬度 } \\
(\mathrm{km})\end{array}$} & \multirow{2}{*}{$\begin{array}{c}\text { 地壳厚度 } \\
(\mathrm{km})\end{array}$} & \multirow{2}{*}{$\begin{array}{c}\text { 垂直形变(膨胀) } \\
\text { 速卒・) } \\
\left(\mathrm{mm} \cdot \mathrm{y}^{-1}\right)\end{array}$} & \multirow{2}{*}{$\begin{array}{c}\text { 横向缩短 (瓜缩) } \\
\text { 速率b) } \\
\left(\mathrm{mm} \cdot \mathrm{y}^{-1}\right)\end{array}$} & \multicolumn{4}{|c|}{ 平均运动速率 $\left(\mathrm{mm} \cdot \mathrm{y}^{-1}\right)$ 和方向 } \\
\hline & & & & & 后缘 & 中部 & 前缘 & 方向 \\
\hline 喜马拉雅褔皱带 & 250 & 60 & 3.7 & 15.4 & $50^{c)}$ & 42.3 & 34.6 & $\sim \mathbf{N}$ \\
\hline 西 藏 块 体 & 450 & 70 & 2.0 & 13.0 & 34.6 & 28.1 & 21.6 & $\sim \mathbf{N}$ \\
\hline 西昆仑山福坡带 & 150 & 65 & 3.0 & 7.0 & 21.6 & 18.1 & 14.6 & $\sim \mathbf{N}$ \\
\hline 塔里木块 体 & 600 & 50 & 0.1 & 1.2 & 14.6 & 14.0 & 13.4 & $\sim \mathbf{N}$ \\
\hline 天山褔䏢带 & 250 & 55 & 2.2 & 10.0 & 13.4 & 8.4 & 3.4 & $\sim \mathrm{N} 10^{\circ} \mathrm{E}$ \\
\hline 准睗尔块体 & 350 & 50 & 0.1 & 0.7 & 3.4 & 3.0 & 2.7 & $\sim \mathrm{N} 10^{\circ} \mathrm{W}$ \\
\hline 横断山襢坡带 & 100 & 55 & 2.0 & 3.6 & $15^{d)}$ & 13.2 & 11.4 & $\sim \mathrm{S} 80^{\circ} \mathrm{E}$ \\
\hline 川滨菱形块体 & 200 & 45 & 1.5 & 6.7 & 11.4 & 8.0 & 4.7 & $\sim \mathrm{S} 70^{\circ} \mathrm{E}$ \\
\hline
\end{tabular}

a) 垂直形变速率=夷平面上升速率十剥蚀速率十均衡速率；b）缩短速率＝垂直形变速率 $\times$ (宽度/厚度)；c）为喜 马拉雅前缘印度板块向北运动速率 (Minster 等, 1978); d) 为西藏块体纵向延伸速率

分析活断层资料可以看出，西藏块体在近南北向缩短、增厚的同时还发生近东西向的延 伸，推挤东邻块体. 其速率可从西藏块体内出现的一系列近南北向张裂带的拉张速率得到估 计, 约为 $10-20 \mathrm{~mm} \cdot \mathrm{y}^{-1}$.

从表 1 的估计值可看出,近三百万年来西藏块体平均向北(或北偏东) 运动速率约 25-28 $\mathrm{mm} \cdot \mathrm{y}^{-1}$. 根据拉萨西北吉果达盆地中吉果达组 $\left(\mathrm{N}_{2}\right)$ 古地磁测定, 该组沉积时古纬度为 $29^{\circ} 4^{\prime}$ $\mathrm{N}$, 现为 $30^{\circ} 7^{\prime} \mathrm{N}^{[7]}$, 向北移动 $31^{\circ} 3^{\prime}$ (约 $118 \mathrm{~km}$ ), 平均速率约为 $31 \mathrm{~mm} \cdot \mathrm{y}^{-1}$, 与我们所得的 估计值相近. 塔里木块体西部以约 $14 \mathrm{~mm} \cdot y^{-1}$ 速率向北运动. 准噶尔块体约以 $3 \mathrm{~mm} \cdot \mathrm{y}^{-1}$ 速率 向北偏西运动. 川滇菱形块体以约 $8 \mathrm{~mm} \cdot \mathrm{y}^{-1}$ 的速率向南东运动. 由于未考虑底部界面摩擦 及纵向延伸变形的吸收, 这些估计值有可能偏大. 但是, 从各块体边界活断层的水平滑动速率 的分布分析,它们大体上是比较符合实际的.

喜马拉雅褶坡带的缩短率约为 $15.4 \mathrm{~mm} \cdot \mathrm{y}^{-1}$, 天山的为 $10 \mathrm{~mm} \cdot \mathrm{y}^{-1}$ 左右. 这些都与 Molnar 等据近 80 年地震资料所得的估计值相近 ${ }^{[2]}$. 西藏块体的 缩短率约为 $13-18 \mathrm{~mm} \cdot \mathrm{y}^{-1}$, 较 Molnar 等的估计值 (4-7 mm $\cdot \mathrm{y}^{-1}$ ) 为大. 但他曾指出其估计值可能偏小, 而大于 $10 \mathrm{~mm} \cdot \mathrm{y}^{-1}$ 是 不足为奇的. 从表 1 还可看出, 准噶尔块体前缘仍可能有约 $2.7 \mathrm{~mm} \cdot \mathrm{y}^{-1}$ 向北偏西的运动. 礽 连山北缘有约 4-12 mm $\cdot \mathrm{y}^{-1}$ 向北东的运动, 西秦岭和六盘山东缘有 $4 \mathrm{~mm} \cdot \mathrm{y}^{-1}$ 向东偏北的运 动, 川滇块体东缘可能有 $5 \mathrm{~mm} \cdot \mathrm{y}^{-1}$ 左右的速率向南东运动。这反映了印度板块向北的推挤对 我国内陆各块体运动和变形的影响范围北可达阿尔泰褶皱带和北山一带, 东可达南北带以 东.

“南北带”作为我国板内块体运动、地壳变形和地震活动的大区分界线是十分突出的. 它 具有复杂的结构，其不同段落的运动状况亦有所差别。它的中南段西侧的各个块体有明显的 向东的侧向挤压. 导致了鄂尔多斯块体向北东运动并作逆时针扭动,华南块体向东南运动,华 北和华南块体之间出现相对的左旋剪切运动. 但由于沿南北带一线地壳及岩石圈结构上的控 
制, 青藏高原向东运动的影响, 在穿过南北带之后, 在中国东部便迅速地减弱了.

在东部，依兰一伊通、邜庐及闽粤沿海北东和北东东走向断裂带都具有明显的逆冲分量，这 反映了我国东部除有向东及向东南运动的趋势外, 东部各块体的运动状况还受到太平洋板块, 尤其是菲律宾海板块向西北运动以及与此相关的弧后扩张的影响. 在台湾和闽县沿海一带, 从东南向西北, 即从沿海向内陆, 活断层滑动速率逐渐变小, 地震活动减弱就明显反映了这一 点.

据地质和地震等资料分析, 华南块体除有向东南方向的运动外, 还具有一定的顺时针方向 的扭动. Molnar 据地震资料估算的华南块体向东南方向的滑动速率约为 $21 \mathrm{~mm} \cdot \mathrm{y}^{-1}$, 看来这 一数值可能偏大. 若距前面求得的青藏高原东侧边缘向东的运动量(表 1) 估算应约为 $5 \mathrm{~mm}$ * $y^{-1}$ 以下.

华北地区块体运动状况比较复杂. 自新第三纪晚期以来, 这里已不是像老第三纪时那样 的引张开裂, 而是已变为以张扭为主的运动了. 这可能与它两侧的蒙古一黑龙江块体和华南块 体之间的相对运动有关 ${ }^{[83}$. 据青藏高原东北侧的西秦岭、祁连山一带的运动速率估计, 华北地 区向北东东方向的运动速率应约为 $4 \mathrm{~mm} \cdot \mathrm{y}^{-1}$ 或更小.

上述对我国板内各块体运动速率的估计值是非常粗精的, 可能存在一倍或更大的误差(不 确定性). 然而它们初步给出了我国现代板内运动状态的一个总体轮廊. 它还需要多方面资 料的补充和修正，包括了诸如利用超长基线测量等新技术方法在我国大陆内部的实地观测与 检验.

\section{參 考韵}

[1] Ding Guo-yu, Quaternary Geology and Environment, China Ocean Press, 1982, 125 -129.

[ 2 ] Molnar, P., Deng Oidong, JGR, 89(1984), B7: 6203-6227.

[ 3 ] Minster, J. B., Jordan, T. H., JGR, 83(1978). B11: 5331-5354.

[4] 漂家全、时振梁等, 地祳学报, 1(1979), 1:9-24.

[5] 刘百簴, 地震地质, 1(1979), 3: 24-40.

[6] 汪素云、许忠淮，地震学报，7(1985)，1:17-32.

[7] 钱方、浦庆余, 吴锡浩, 青藏高原地质文集, 第 4 集, 地质出版社, 1982, 34-50.

[ 8 ] Zonenshain, L. P., Savostin, L. A., Tectonophysics, 76(1981), 1-2: 1-45. 